\title{
Effect of spectinomycin on T. pallidum in incubating experimental syphilis
}

\author{
D. PETZOLDT
}

From the University Dermatological Clinic, Münich, and The Department of Dermatology, Medical University

of Lübeck, W. Germany

Spectinomycin is an effective drug in the treatment of gonorrhoea. It is recommended when penicillin and ampicillin are contraindicated or ineffective. The total dose of $2 \mathrm{~g}$. in men or $\mathbf{4} \mathrm{g}$. in women is given at one visit.

Patients with manifest gonorrhoea may also have inapparent incubating syphilis. This paper reports the results of animal experiments designed to determine whether blood levels produced by a single dose of $2 \mathrm{~g}$. spectinomycin in man are sufficient to cure a simultaneously acquired incubating syphilis.

\section{Material and methods}

Ten male rabbits weighing 2.5 to $3 \mathrm{~kg}$. were infected intratesticularly with a suspension of 300 treponemes of the Nichols strain of $T$. pallidum determined by the method of Morgan and Vryonis (1938). Treponemes were suspended in $0.2 \mathrm{ml}$. of a medium made up as follows:

\begin{tabular}{lc}
\multicolumn{1}{c}{ Component } & Percentage \\
Rabbit-serum (inactivated) & $25 \cdot 0$ \\
$\mathrm{Na}_{2} \mathrm{HPO}_{4}$ & 0.18 \\
$\mathrm{KH}_{2} \mathrm{PO}_{4}$ & 0.025 \\
Sodium pyruvate & 0.005 \\
Sodium thioglycollate & 0.06 \\
Cystein hydrochloride & 0.01 \\
NaHCO $_{3}$ & 0.03 \\
Glutathione (reduced) & 0.015 \\
0.9 per cent. $\mathrm{NaCl}$ & ad 50.0
\end{tabular}

3 days after infection five of the rabbits were treated with spectinomycin. In order to achieve serum levels in the laboratory animals similar to those in patients who had received $2 \mathrm{~g}$. in a single dose, it was necessary to inject $1.1 \mathrm{~g}$. spectinomycin in two doses. An initial dose of $0.8 \mathrm{~g}$. was followed by a second dose of $0.3 \mathrm{~g} .4 \mathrm{hrs}$ later (Fig. 1). Spectinomycin serum levels were determined by serial dilution test ( $\mathrm{pH} 8$ ), using $E$. coli UC 527 (minimum inhibitory concentration: 3.2 to $3.8 \mu \mathrm{g} . / \mathrm{ml}$.).

After treatment, the rabbits were examined at about weekly intervals for clinical and serological signs of developing syphilis. The testicles were palpated and quantitative serum FTA-ABS tests were carried out. The study was concluded 12 weeks after the initial inoculation.

Received for publication January 27, 1975

This work was supported by the Deutsche Forschungsgemeinschaft Address for reprints: Ratzeburger Allee 160, 24 Lübeck 1, W. Germany

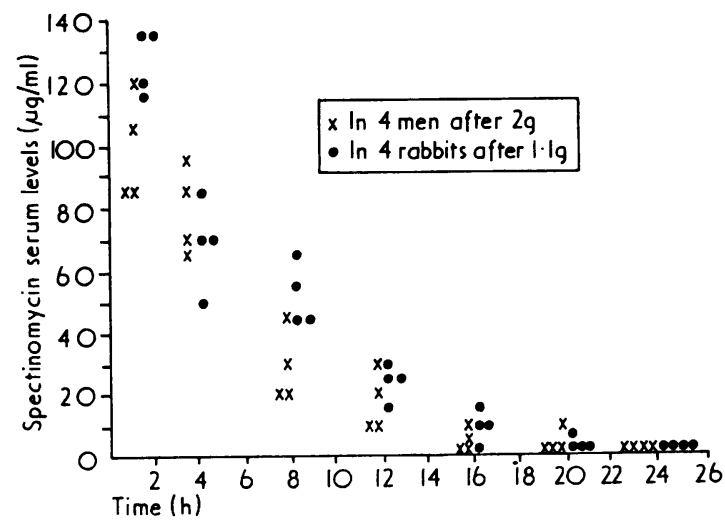

FIG. 1 Spectinomycin serum levels

\section{Results}

After an incubation period of 4 to 6 weeks, all the rabbits-treated as well as untreated-developed syphilitic orchitis, and the titres of the FTA-ABS tests increased. There was, however, a distinct difference between the rabbits treated with spectinomycin on one hand and the untreated controls on the other. Both syphilitic orchitis and increasing FTA-ABS titres appeared about 2 wks later in the

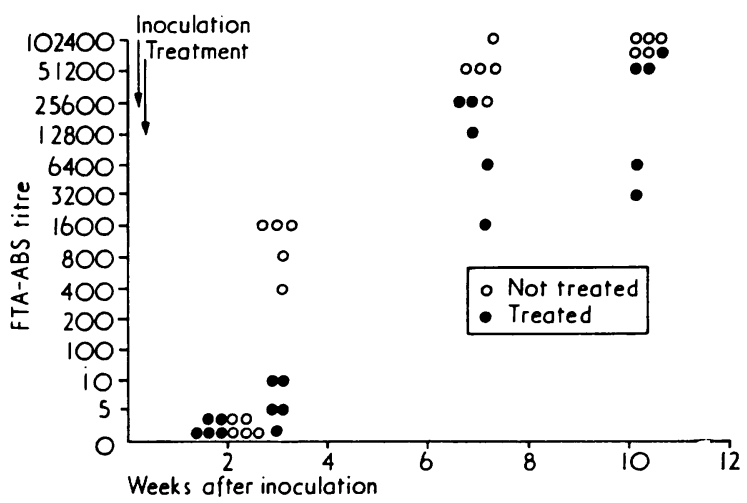

FIG. 2 FTA-ABS titres in experimental syphilis in rabbits 
treated animals than in the untreated controls. Even 10 wks after inoculation there was a slight difference between FTA-ABS titres of the two groups of animals (Fig. 2).

\section{Discussion}

Previous experimental investigations have shown that single doeses of $4 \mathrm{~m} . \mathrm{u}$. aqueous penicillin-G-Na, $2.5 \mathrm{~g}$. thiamphenicol, or the combination of $1.4 \mathrm{~g}$. pivampicillin and $1 \mathrm{~g}$. probenecid are able to cure a very early incubating syphilis. This means that, in cases of double infection with gonorrhoea and syphilis, single doses of these antibiotics are sufficient to cure both acute gonorrhoea and a simultaneously acquired syphilis (Petzoldt, 1972a, 1975).

The results of the present study, however, show, that a single dose of spectinomycin has little effect on $T$. pallidum; spectinomycin did not cure incubating syphilis in the rabbits when administered in a dosage corresponding to a single dose of $2 \mathrm{~g}$. in man. In this respect the effect of a single-dose treatment with spectinomycin is equal to the effect of a single-dose treatment with $300 \mathrm{mg}$. doxycycline (Petzoldt, 1972b).

The fact that both the syphilitic orchitis and the increasing FTA-ABS titres appeared about 2 wks later in the animals treated with spectinomycin than in the untreated controls indicates that spectinomycin either diminished the number of inoculated treponemes or delayed their reduplication, but did not eradicate them.

Clark and Yobs (1964) studied the effect of spectınomycin by a method very similar to ours. They too attempted to simulate experimentally the effect of a single-dose treatment with spectinomycin for acute gonorrhoea on incubating syphilis acquired during the same exposure. Our investigation also takes into consideration that not only the number of treponemes and the interval between inoculation and treatment are simulated but also the spectinomycin serum levels.
Despite this difference in methods, the results of the two studies and also those of Antonescu and Popescu (1974), who worked with large numbers of treponemes $\left(10^{5}\right.$ and $\left.10^{6}\right)$, are in general the same. They indicate that the single-dose treatment with spectinomycin has a moderate effect on $T$. pallidum which definitely prolongs the subclinical incubation period of syphilis, but does not, as a rule, cure incubating syphilis completely.

\section{Summary}

Animal experiments were performed to determine if a single-dose treatment for acute gonorrhoea with $2 \mathrm{~g}$. spectinomycin could cure a simultaneously acquired syphilis at a very early stage of incubation. 300 treponemes (Nichols stain T. pallidum) were inoculated intratesticularly and 3 days later spectinomycin was administered in a dose which produced spectinomycin serum levels similar to those in patients who had received a single oral dose of $2 \mathrm{~g}$.

This dosage of spectinomycin did not prevent the development of syphilitic orchitis or reactivity to the FTA-ABS test, but it prolonged the subclinical incubation period.

We gratefully acknowledge the technical assistance of Miss A. Hess, Mrs. I. Kiefl, and Mrs. D. Nau.

\section{References}

Antonescu, S., and Popescu, A. (1974) 'Der Einfluss einer Einzeitgabe Spectinomycin auf die experimentelle Kaninchensyphilis'. Vortrag 'Berliner StaniloGespräche', Berlin, 29.11.1974

Clark, J. W., and YoBs, A. R. (1964) Brit. F. vener. Dis., 40, 53

Morgan, H. J., and VRYonis, G. P. (1938) Amer. f. Syph., 22,462

Petzoldt, D. (1972a) Postgrad. med. F., 48, (Jan. Suppl.), p. 61

_- (1972b) Brit. F. vener. Dis., 48, 514

- (1975) Hautarzt, 26, in press 